\title{
Prognosis for Ambulation in Cerebral Palsy: A Population-Based Study
}

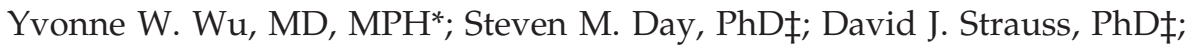 \\ and Robert M. Shavelle, PhD, MBA
}

\begin{abstract}
Objectives. To determine independent predictors of ambulation among children with cerebral palsy and to develop a simple tool that estimates the probability that a child will walk.

Methods. In a retrospective study of all children with cerebral palsy who were not yet walking at 2 to $3 \frac{1}{2}$ years of age, while receiving services from the California Department of Developmental Services during the years 1987-1999, we analyzed medical and functional data obtained annually by Department of Developmental Services physicians and social workers. Using logistic regression analyses, we determined independent predictors of a child's ability to walk well alone at least 20 feet, without assistive devices, by age 6 . We then estimated the probabilities of walking at various levels of ability over time, using multistate survival analysis.

Results. Of 5366 study subjects, $2295(43 \%)$ were evaluated at age $6 ; 12.8 \%$ could walk independently and $18.4 \%$ walked with support. Independent predictors of successful ambulation included early motor milestones such as sitting (odds ratio: $12.5 ; 95 \%$ confidence interval: 5.8-27.2) and pulling to a stand (odds ratio: 28.5 ; $95 \%$ confidence interval: 13.4-60.4) when compared with lack of rolling at age 2, cerebral palsy type other than spastic quadriparesis (odds ratio: $2.2 ; 95 \%$ confidence interval: 1.5-3.1), and preserved visual function (odds ratio: 2.4; 95\% confidence interval: 1.1-5.4). Our ambulation charts depict the probability of remaining nonambulatory, transitioning to 1 of 3 possible ambulatory states, or expiring at all subsequent ages through age 14 .

Conclusion. The ambulation charts provide a simple straightforward way to estimate the probability that a child with cerebral palsy who is nonambulatory at 2 to $3 \frac{1 / 2}{2}$ years of age will eventually walk with or without support. Pediatrics 2004;114:1264-1271; cerebral palsy, ambulation, prognosis.
\end{abstract}

ABBREVIATIONS. GMFCS, Gross Motor Function Classification System; GMFM, Gross Motor Function Measure; CDER, Client Development Evaluation Report; DDS, Department of Developmental Services.

\footnotetext{
From the *Departments of Neurology and Pediatrics, University of California, San Francisco, California, and the $\ddagger$ University of California Life Expectancy Project, San Francisco, California.

Accepted for publication May 6, 2004.

doi:10.1542/peds.2004-0114

Address correspondence to Yvonne W. Wu, MD, MPH, Division of Child Neurology, Box 0136, University of California-San Francisco, 500 Parnassus Ave, Room 411, San Francisco, CA 94143-0136. E-mail: wuy@neuropeds. ucsf.edu

PEDIATRICS (ISSN 0031 4005). Copyright @ 2004 by the American Academy of Pediatrics.
}

$\mathrm{P}$ arents of children with cerebral palsy frequently ask whether their children will ever walk. For health care providers of children with cerebral palsy, knowledge of future ambulatory potential may help establish appropriate treatment plans and long-range goals.

Previous studies of ambulation in cerebral palsy involved relatively small numbers of patients recruited from single clinics, ${ }^{1-7}$ and the results were sometimes conflicting. For example, estimates of the percentage of children with spastic quadriplegia who might eventually walk ranged from $0 \%$ to $72 \%$, depending on the study population and study design. $3,4,7$

The validated Gross Motor Function Classification System (GMFCS), ${ }^{8}$ with motor development curves based on the Gross Motor Function Measure (GMFM), ${ }^{9,10}$ have improved our understanding of gross motor development among children with cerebral palsy. However, we still lack a simple tool for predicting ambulation among children with cerebral palsy. The GMFM calculates a score from 66 to 88 separate items. ${ }^{11}$ Although the majority of children at GMFCS levels I and II will achieve the ability to walk 10 steps unsupported whereas less than onehalf of children at GMFCS levels III, IV, and V will do so, ${ }^{10}$ the exact probabilities of ambulating, with and without support, based on GMFCS levels have not been reported. Finally, the GMFCS level determined in the first years of life was shown to predict walking ability at age 6 to $12^{12}$; however, $>38 \%$ of the 85 study participants were already walking, with or without support, at 2 to 4 years of age, and the positive predictive value of GMFCS level for ambulation among individuals with more severe motor disability was as low as $62 \%$.

Certain clinical characteristics may be useful in predicting future ambulation, including location and type of cerebral palsy, presence of epilepsy, degree of cognitive impairment, and underlying cause of cerebral palsy. 4,5,7,13 To our knowledge, no study has yet evaluated the independent or combined contributions of these factors. Therefore, more data are needed to generate estimates of prognosis for ambulation for children with cerebral palsy. In a retrospective cohort study of 5366 children with cerebral palsy who were not yet walking at 2 to $3 \frac{1}{2}$ years of age, we set out to determine predictors of ambulation and to develop a simple tool for estimating the probability that a child will walk. 


\section{METHODS}

\section{Study Population}

Our retrospective cohort consisted of all children with cerebral palsy who were not yet walking at 2 to $3^{1 / 2}$ years of age (henceforth referred to as age 2), when they received services from the State of California Department of Developmental Services (DDS), between January 1, 1987, and December 31, 1999. The DDS provides early intervention, occupational and physical therapy, equipment, case management, respite care, and social services for all state residents with substantive disability resulting from cerebral palsy. ${ }^{14}$ Cerebral palsy is defined as "a group of nonprogressive lesions or disorders in the brain characterized by paralysis, spasticity, or abnormal control of movement or posture, such as poor coordination or lack of balance. These disorders may be due to developmental anomalies of the central nervous system or injury of the brain during intrauterine life, the perinatal period, or within the first few months of life, and are manifest prior to age 2 or 3 years."15(pVI.6.1)

\section{Measurements}

Each year, individuals receiving services from DDS undergo a comprehensive evaluation that generates a document called the Client Development Evaluation Report (CDER). ${ }^{15(\mathrm{pVI} .24 .6)}$ This report contains $>200$ medical, functional, behavioral, and cognitive items and is completed by physicians and social workers. A staff physician records data regarding medical diagnoses such as cerebral palsy and epilepsy, whereas a social worker determines the child's functional, behavioral, and cognitive status. The data are obtained through interviews with family members or the child's caregivers, as well as through observation of the child when possible. The inter-rater reliabilities for the motor function variables in the CDER exceed $0.85 .{ }^{16}$

We electronically searched all CDER records collected during the study period for children with cerebral palsy who were assigned an ambulation level of "does not walk" at age 2 years. If a child received 2 evaluations within this age range, we used data from the earlier evaluation only. We were interested in congenitally acquired cerebral palsy and therefore excluded children with diagnoses suggesting cerebral palsy of postnatal origin (traumatic brain injury, near-drowning, motor vehicle accident, brain tumor, and other acquired injuries), as well as children with diagnoses suggesting an underlying disorder other than cerebral palsy (autism and degenerative disorders). The remaining children constituted the final study population.

\section{Clinical Information}

Several clinical factors were considered potentially useful in predicting ambulation. These included type of cerebral palsy (spastic, ataxic, dyskinetic including dystonia and choreoathetosis, hypotonic, or other), distribution of limb involvement (quadriplegia, diplegia, hemiplegia, triplegia, monoplegia, or other), presence of spastic quadriplegia (yes or no), gross motor function (rolling, sitting, and standing milestones), expressive language (use of words versus no use of words), hand use (raking motion or better versus no functional use), ability to feed self (does so independently, needs assistance, or unable), history of seizures (yes or no), and legal blindness (yes or no).

\section{Outcome Measures}

We defined full ambulation as the ability to walk well alone at least 20 feet without assistive devices, on the basis of the CDER definition for ambulation at level 4, ie, "Walks well alone at least twenty (20) feet; also balances well. Clients who have an unusual or awkward gait but who are not in danger of stumbling or falling should also be rated at this level.... If a client typically uses a wheelchair, rate at level 1 (no ambulation)."15

First we analyzed full ambulation at age 6 as a dichotomous outcome, among all children who survived and received a CDER evaluation at age 6 during the study years. Then we considered 3 levels of ambulation, ie, 1) walks with support or assistive devices, 2) walks unsteadily alone at least 10 feet without assistive devices, and 3) walks well alone at least 20 feet without assistive devices (full ambulation). We determined the probability of each of these outcomes at various follow-up times by using multistate survival techniques (see below).
Mortality information was obtained from annual computer files from the State of California (1987-1999) and was linked to the subjects in our study population on the basis of name, date of birth, and Social Security number when available. All children who stopped receiving an annual evaluation within the DDS and who were not identified in the state mortality database were considered to be lost to follow-up monitoring.

\section{Statistical Methods}

We used logistic regression ${ }^{17}$ to determine predictors of full ambulation at age 6 . All significant $(P<.05)$ predictors of ambulation in the univariate analyses were entered into the multivariate model, and backward elimination was then used to determine the variables most significantly and independently predictive of future ambulation $(P<.10$ was used as the cutoff for retention in the model). Possible interactions were considered.

Next we estimated the probabilities of ambulation at various levels (eg, with and without support) at all ages through age 14, using Aalen-Johansen estimators of long-term transition probabilities. ${ }^{18,19}$ This nonparametric technique of multistate survival analysis accounts for censoring and death and is similar to the KaplanMeier estimator used in simple survival analyses. ${ }^{19}$ With this technique, we created "ambulation charts" that illustrate the probabilities for different states of ambulation with time. ${ }^{20-22}$

Finally, we partitioned the study cohort into 4 mutually exclusive groups on the basis of the early motor milestones that were found to be most strongly predictive of future ambulation. For each of these subgroups, a separate ambulation chart was created to illustrate the prognosis for ambulation specific to each group. All statistical analyses were performed with SAS statistical analysis software (version 6.12; SAS Institute, Cary, NC), and figures were created with S-Plus (version 4.0; MathSoft, Seattle, WA). All study procedures were approved by the institutional review board of the University of California, San Francisco.

\section{RESULTS}

\section{Description of Cohort}

We identified 6480 children with cerebral palsy who were nonambulatory at age 2 (Fig 1). After exclusion of those with an exclusion diagnosis, the remaining 5366 children constituted our study cohort.

The mean age at entry into the study was 2.7 years (SD: 0.4 years), and male subjects represented $56 \%$ of the study population (Table 1). At initial evaluation, more than one-third of the children could not roll over, $25 \%$ could roll but not sit, and approximately one-third could sit with minimal or no support. The majority $(80 \%)$ had some functional hand use, although most could not feed themselves. One-quarter of the children exhibited at least some expressive language, $12 \%$ were legally blind, and 20\% had a history of seizures. Spastic quadriplegia was the most common type of cerebral palsy, constituting $46 \%$ of our study population.

\section{Univariate Analyses}

The mean follow-up period was 5.8 years (SD: 3.6$)$, and a total of 348 children (6.8\%) had expired by the end of the study period. Of the 2295 children (43\%) who were alive and evaluated at age 6, 8.5\% had achieved full ambulation (could walk well alone at least 20 feet without assistive devices), 4.3\% could walk unsteadily alone at least 10 feet without assistive devices, and $18.4 \%$ could walk with support or assistive devices. Children whose outcomes at age 6 were not available included 1128 (21\%) who were not yet 6 years of age at the end of the study period, 857 (16\%) who were seen after age 7 but had not undergone a CDER evaluation at age 6, 793 (15\%) who 


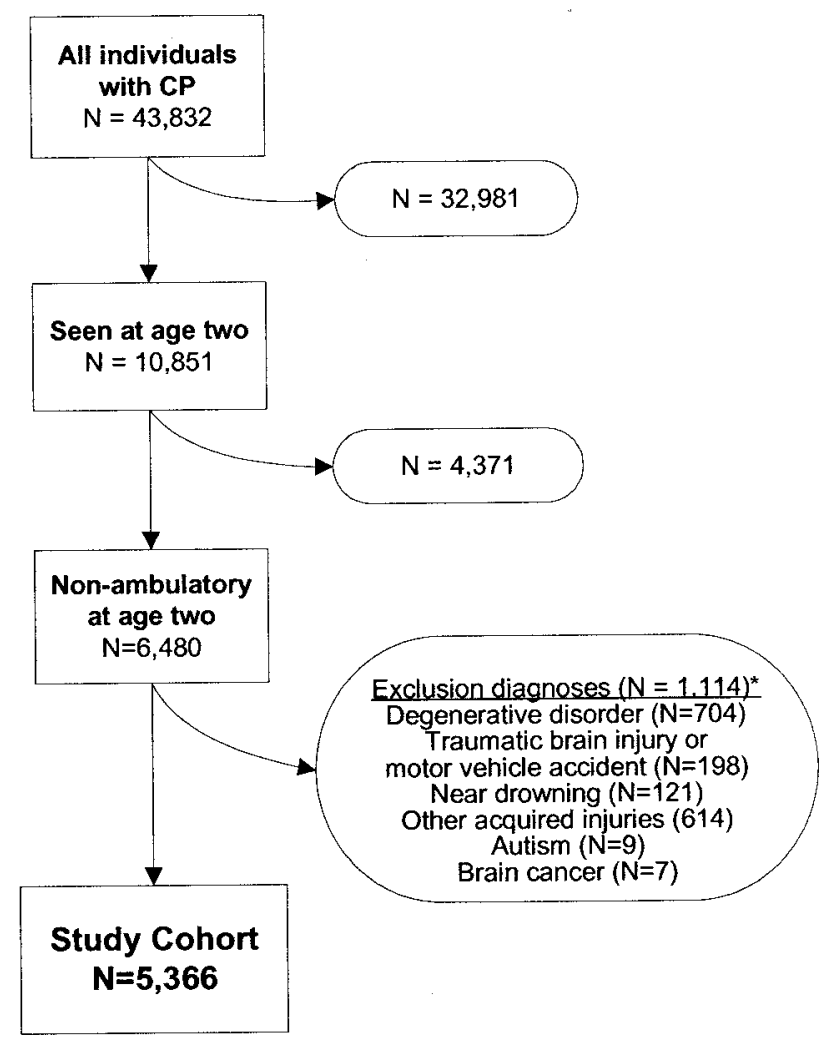

Fig 1. Selection of the study cohort. * Children who were excluded sometimes had $>1$ exclusion diagnosis.

were lost to follow-up monitoring, and 293 (6\%) who had expired by age 6 .

Univariate predictors for full ambulation included type and location of cerebral palsy, motor and language function, and presence of visual impairment (Table 2). As expected, motor milestones were particularly strong predictors of eventual ambulation. For instance, the odds of achieving full walking were 26 times higher for children who were sitting without support at 2 years of age than for those who could not yet roll over at the initial evaluation. Ataxia and hypotonic cerebral palsy were associated with better prognoses for future ambulation than were spastic and dyskinetic cerebral palsy. Increasing hand function, the ability to feed self or say simple words, lack of visual impairment, and lack of seizures were also associated with better chances of achieving full ambulation.

\section{Multivariate Analysis}

To determine independent predictors of ambulation, we entered all factors associated with ambulation in the univariate analyses into a logistic regression model. The clinical factors independently associated with successful ambulation at age 6 included early motor milestones such as the ability to sit or pull to a stand, the absence of spastic quadriplegia, and the absence of blindness (Table 3). Other variables, such as hand use, expressive language, and epilepsy, did not provide additional information beyond that obtained from the significant predictors identified in the multivariate model.
TABLE 1. Clinical Characteristics of 5366 Children With Cerebral Palsy Who Were Nonambulatory at 2 Years of Age

\begin{tabular}{|c|c|c|}
\hline & No. & $\%$ \\
\hline \multicolumn{3}{|l|}{ Gender } \\
\hline Male & 3029 & 56.4 \\
\hline Female & 2337 & 43.6 \\
\hline \multicolumn{3}{|l|}{ Ethnicity } \\
\hline White & 1849 & 34.5 \\
\hline Hispanic & 1946 & 36.3 \\
\hline Black & 535 & 10.0 \\
\hline Asian & 242 & 4.5 \\
\hline Other & 454 & 8.5 \\
\hline Unspecified & 340 & 6.3 \\
\hline \multicolumn{3}{|l|}{ Type of motor dysfunction } \\
\hline Spasticity & 3348 & 62.4 \\
\hline Ataxia & 110 & 2.1 \\
\hline Dyskinesis (dystonia or athetosis) & 120 & 2.2 \\
\hline Hypotonia & 884 & 16.5 \\
\hline Other (including mixed) & 904 & 16.9 \\
\hline \multicolumn{3}{|l|}{ Location of motor dysfunction } \\
\hline Quadriplegia & 3733 & 69.6 \\
\hline Diplegia & 633 & 11.8 \\
\hline Hemiplegia & 310 & 5.8 \\
\hline Monoplegia & 83 & 1.5 \\
\hline Triplegia & 62 & 1.2 \\
\hline Other & 545 & 10.2 \\
\hline \multicolumn{3}{|l|}{ Rolling and sitting } \\
\hline Does not roll over & 2086 & 38.9 \\
\hline Rolls front to back only & 331 & 6.2 \\
\hline Rolls front to back and back to front & 981 & 18.3 \\
\hline Sits with support at least $5 \mathrm{~min}$ & 717 & 13.3 \\
\hline Sits independently at least $5 \mathrm{~min}$ & 433 & 8.1 \\
\hline Assumes and maintains sitting position & 818 & 15.2 \\
\hline \multicolumn{3}{|l|}{ Crawling and standing } \\
\hline Does not crawl, creep, or scoot & 3155 & 58.8 \\
\hline Crawls, creeps, or scoots & 1370 & 25.5 \\
\hline Pulls to a stand & 320 & 6.0 \\
\hline Stands with support $1 \mathrm{~min}$ & 442 & 8.2 \\
\hline Stands unsteadily alone $1 \mathrm{~min}$ & 47 & 0.9 \\
\hline Stands well alone $5 \mathrm{~min}$ & 32 & 0.6 \\
\hline \multicolumn{3}{|l|}{ Hand use } \\
\hline No functional use of hand & 1091 & 20.3 \\
\hline Rakes or grasps with hand & 2574 & 48.0 \\
\hline Has pincer grasp & 911 & 17.0 \\
\hline Uses fingers independently & 790 & 14.7 \\
\hline \multicolumn{3}{|l|}{ Eating } \\
\hline Does not feed self & 3352 & 62.5 \\
\hline Finger-feeds but needs assistance & 762 & 14.2 \\
\hline Finger-feeds self without assistance & 1252 & 23.3 \\
\hline \multicolumn{3}{|l|}{ Expressive language } \\
\hline Uses no words & 4027 & 75.0 \\
\hline Says simple words at least & 1339 & 25.0 \\
\hline \multicolumn{3}{|l|}{ Vision } \\
\hline Legally blind & 663 & 12.4 \\
\hline Not legally blind & 4703 & 87.6 \\
\hline \multicolumn{3}{|l|}{ Seizures } \\
\hline Seizures within the past year & 916 & 17.0 \\
\hline History of seizures, none in past year & 186 & 3.5 \\
\hline No history of seizures & 4264 & 79.5 \\
\hline
\end{tabular}

\section{Ambulation Charts}

We then graphed the probabilities of achieving 3 levels of ambulation at various follow-up times. The resulting ambulation chart (Fig 2) illustrates the probability of remaining nonambulatory at subsequent ages or transitioning to 1 of the 4 possible states (expired, walks with support or assistive devices, walks unsteadily alone at least 10 feet without assistive devices, or walks well alone at least 20 feet without assistive devices). The ambulatory outcomes at age 7 can be determined by examining the vertical line depicted in Fig 2. As indicated by the line segments designated with the letters $\mathrm{A}$ through $\mathrm{F}$, the 
TABLE 2. Univariate Odds Ratios for Achieving Full Ambulation by 6 Years of Age Among 2295 Children With Cerebral Palsy Who Were Nonambulatory at 2 Years of Age

\begin{tabular}{|c|c|c|c|}
\hline & Odds Ratio & 95\% Confidence Interval & $P$ Value \\
\hline \multicolumn{4}{|l|}{ Gender } \\
\hline Male & 1.0 & Ref & Ref \\
\hline Female & 1.0 & $0.7-1.3$ & .82 \\
\hline \multicolumn{4}{|l|}{ Ethnicity } \\
\hline White & 1.0 & Ref & Ref \\
\hline Hispanic & 1.2 & $0.8-1.7$ & .43 \\
\hline Black & 1.5 & $0.9-2.4$ & .10 \\
\hline Asian & 1.4 & $0.7-2.7$ & .31 \\
\hline Other & 1.2 & $0.7-2.2$ & .48 \\
\hline Unspecified & 1.3 & $0.7-2.4$ & .50 \\
\hline \multicolumn{4}{|l|}{ Type of motor dysfunction } \\
\hline Spasticity & 1.0 & Ref & Ref \\
\hline Ataxia & 3.7 & $1.7-8.3$ & .001 \\
\hline Dyskinesis (dystonia or athetosis) & 1.0 & $0.3-3.2$ & .96 \\
\hline Hypotonia & 2.4 & $1.7-3.5$ & .001 \\
\hline Other (including mixed) & 1.7 & $1.2-2.5$ & .01 \\
\hline \multicolumn{4}{|l|}{ Location of cerebral palsy } \\
\hline Quadriplegia & 1.0 & Ref & Ref \\
\hline Diplegia & 2.4 & $1.6-3.6$ & .0001 \\
\hline Hemiplegia & 4.3 & $2.7-6.7$ & .0001 \\
\hline Monoplegia & 3.3 & $1.3-8.2$ & .01 \\
\hline Triplegia & 1.9 & $0.6-6.5$ & .29 \\
\hline Other & 2.0 & $1.3-3.2$ & .002 \\
\hline \multicolumn{4}{|l|}{ Spastic quadriplegia } \\
\hline Present & 1.0 & Ref & Ref \\
\hline Absent & 3.5 & $2.4-4.9$ & .0001 \\
\hline \multicolumn{4}{|l|}{ Rolling and sitting } \\
\hline Does not roll over & 1.0 & Ref & Ref \\
\hline Rolls but does not sit & 4.2 & $1.9-9.1$ & .0003 \\
\hline Sits with support & 7.6 & $3.4-16.9$ & .0001 \\
\hline Sits without support & 26.1 & $12.6-54.0$ & .0001 \\
\hline \multicolumn{4}{|l|}{ Crawling and standing } \\
\hline Does not crawl, creep, or scoot & 1.0 & Ref & Ref \\
\hline Crawls, creeps, or scoots & 3.1 & $2.1-4.6$ & .0001 \\
\hline Pulls to a stand at least & 9.8 & $6.7-14.4$ & .0001 \\
\hline \multicolumn{4}{|l|}{ Hand use } \\
\hline No functional use of hand & 1.0 & Ref & Ref \\
\hline Uses raking motion or grasps & 5.1 & $2.2-11.7$ & .0002 \\
\hline Has pincer grasp & 10.5 & $4.4-24.6$ & .0001 \\
\hline Uses fingers independently & 15.6 & $6.7-36.6$ & .0001 \\
\hline \multicolumn{4}{|l|}{ Eating } \\
\hline Does not feed self & 1.0 & Ref & Ref \\
\hline Finger-feeds but needs assistance & 1.8 & $1.2-2.9$ & .007 \\
\hline Finger-feeds without assistance & 2.9 & $2.1-4.0$ & .0001 \\
\hline \multicolumn{4}{|l|}{ Expressive language } \\
\hline Uses no words & 1.0 & Ref & Ref \\
\hline Says simple words at least & 2.1 & $1.5-2.8$ & .0001 \\
\hline \multicolumn{4}{|l|}{ Vision } \\
\hline Legally blind & 1.0 & Ref & Ref \\
\hline Not legally blind & 3.7 & $1.7-8.0$ & .001 \\
\hline \multicolumn{4}{|l|}{ Epilepsy } \\
\hline Seizures within the past year & 1.0 & Ref & Ref \\
\hline History of seizures, none in past year & 0.3 & $0.1-1.4$ & .09 \\
\hline No history of seizures & 1.1 & $0.7-1.6$ & .73 \\
\hline
\end{tabular}

Odds ratios refer to the odds of being able to walk well alone at least 20 feet without assistive devices, compared with the odds of not doing so by age 6 . Ref indicates the reference group, with odds ratio of 1.0 by definition.

majority of children still could not walk by age 7 and $8 \%$ had expired. Of the $27 \%$ who had achieved ambulation by age 7 , approximately one-third could walk without support (Table 4).

We then created 4 separate ambulation charts, each depicting the ambulatory potential of children sharing a similar motor developmental profile at 2 years of age (Fig 3). As expected, children who were not rolling by age 2 years demonstrated the lowest probability of achieving ambulation and the highest mortality rate. However, a small proportion $(2 \%)$ of these children did eventually walk without support by age 7 (Table 4). Similarly, among children who were unable to sit independently but who could roll at the study onset, $7 \%$ could walk without support by age 7 and an additional $20 \%$ could walk with support. For children who were already pulling to a stand by 2 years of age, the likelihood of walking with or without support by age 7 was as high as $75 \%$. In a separate analysis, we found that, among all children who were alive, uncensored, and fully ambulatory at age $10,65 \%$ had become fully ambulatory by age 6 and $96 \%$ had at least walked with support by age 6 . 
TABLE 3. Multivariate Odds Ratios for Achieving Full Ambulation by 6 Years of Age Among 2295 Children With Cerebral Palsy Who Were Nonambulatory at 2 Years of Age

\begin{tabular}{lccc}
\hline & Odds Ratio & $95 \%$ Confidence Interval & $P$ Value \\
\hline Motor milestones & & & \\
$\quad$ Does not roll & 1.0 & Ref & Ref \\
Rolls, does not sit without support & 4.6 & $2.2-9.6$ & .0001 \\
$\quad$ Sits without support, ${ }^{*}$ does not stand & 12.5 & $5.8-27.2$ & .0001 \\
$\quad$ Pulls to stand & 28.5 & $13.4-60.4$ & .0001 \\
Type of cerebral palsy & 1.0 & Ref & Ref \\
$\quad$ Spastic quadriplegia & 2.2 & $1.5-3.1$ & .0001 \\
Other & & & Ref \\
Vision & 1.0 & Ref & .03 \\
$\quad$ Totally or legally blind & 2.4 & $1.1-5.4$ & \\
$\quad$ Not blind
\end{tabular}

Odds ratios refer to the odds of being able to walk well alone at least 20 feet without assistive devices, compared with the odds of not doing so by 6 years of age. Ref indicates reference group, with odds ratio of 1.0 by definition.

* Sitting refers to the ability to maintain a sitting position without support or the ability to achieve a sitting position on one's own.
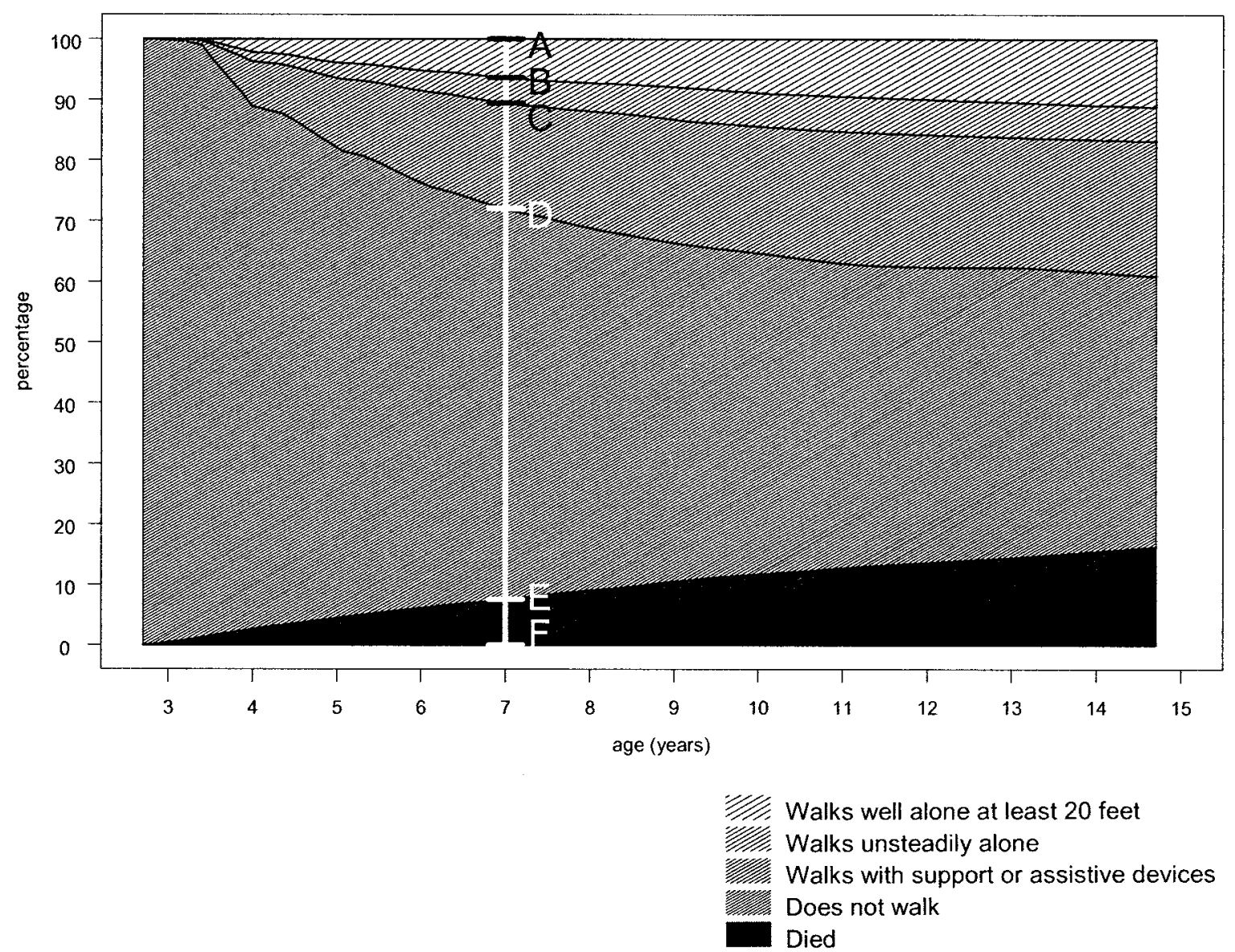

Fig 2. Ambulation chart showing probabilities of various levels of ambulation with time for children who were initially nonambulatory at a mean age of 2.7 years. Letters A through F indicate the various percentages of the 5 possible outcomes at age 7 (Table 4 ).

\section{DISCUSSION}

In this largest study of cerebral palsy and ambulation reported to date, we found that, among children who were not yet walking at age $2,10 \%$ were able to walk independently by age 6 to 7 and an additional $17 \%$ could walk with support. The clinical factors most useful in predicting future ambulation were motor milestones at age 2 (ability to roll, sit, or stand), the type of cerebral palsy, and blindness. On the basis of motor function at age 2, the prognosis for future ambulation can be determined at each subsequent year of age with ambulation charts that reflect the experience of 5366 children with cerebral palsy, 3152 of whom were monitored past age 6 .

Previous studies of cerebral palsy focused on persistent primitive reflexes, levels of motor function, and clinical type of cerebral palsy as predictors of future ambulation. ${ }^{4-7,13}$ The ability to sit by 2 years of age was emphasized as a particularly strong predictor of ambulation. For instance, pre- 
TABLE 4.

Probability of Walking at 7 Years of Age, Stratified by Motor Milestones at 2 Years of Age

\begin{tabular}{|c|c|c|c|c|c|c|}
\hline \multirow{2}{*}{$\begin{array}{l}\text { Ambulation } \\
\text { at Age } 7\end{array}$} & \multirow{2}{*}{$\begin{array}{l}\text { Vertical } \\
\text { Segment* }\end{array}$} & \multicolumn{5}{|c|}{ Probability, \% } \\
\hline & & $\begin{array}{l}\text { Entire Cohort } \\
\quad(N=5366)\end{array}$ & $\begin{array}{l}\text { Does Not Roll } \\
\quad(N=1733)\end{array}$ & $\begin{array}{c}\text { Rolls, Does } \\
\text { Not Sitt } \\
(N=2382)\end{array}$ & $\begin{array}{c}\text { Sits, Cannot Pull } \\
\text { to Stand } \\
(N=636)\end{array}$ & $\begin{array}{l}\text { Pulls to Stand } \\
\qquad(N=615)\end{array}$ \\
\hline Walks well alone & $\mathrm{AB}$ & 6 & 1 & 4 & 11 & 28 \\
\hline Walks unsteadily alone & $\mathrm{BC}$ & 4 & 1 & 3 & 8 & 16 \\
\hline Walks with support & $\mathrm{CD}$ & 17 & 5 & 20 & 31 & 32 \\
\hline Does not walk & $\mathrm{DE}$ & 64 & 78 & 68 & 47 & 23 \\
\hline Died & $\mathrm{EF}$ & 8 & 15 & 5 & 2 & 2 \\
\hline
\end{tabular}

* Refers to vertical segments depicted on Figure 2.

t Sitting refers to the ability to maintain a sitting position without support or the ability to achieve a sitting position on one's own.

a. Does not roll $(n=1733)$

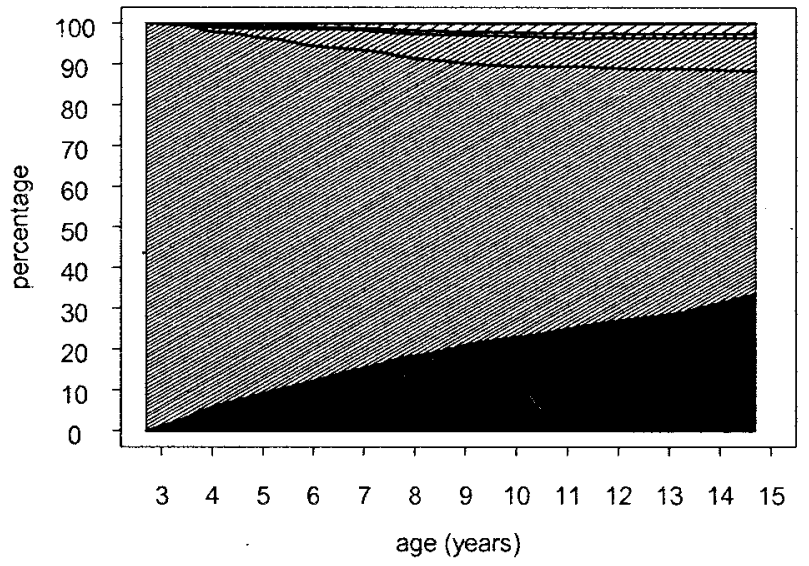

c. Rolls and sits, does not pull to stand

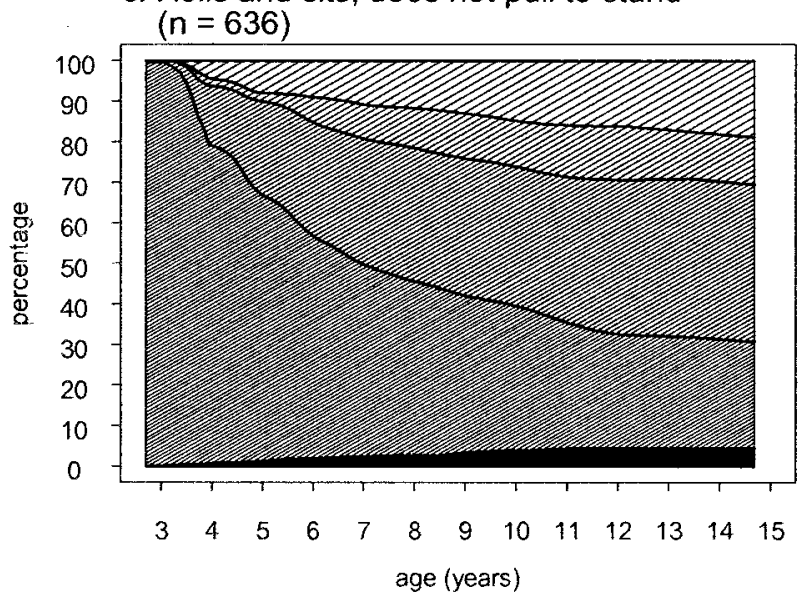

b. Rolls, but does not sit $(n=2382)$

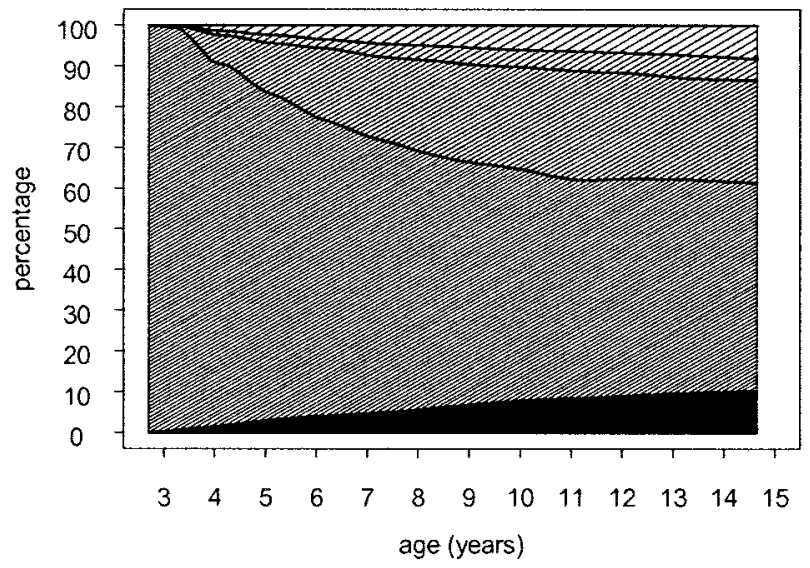

d. Rolls, sits and pulls to stand $(n=615)$

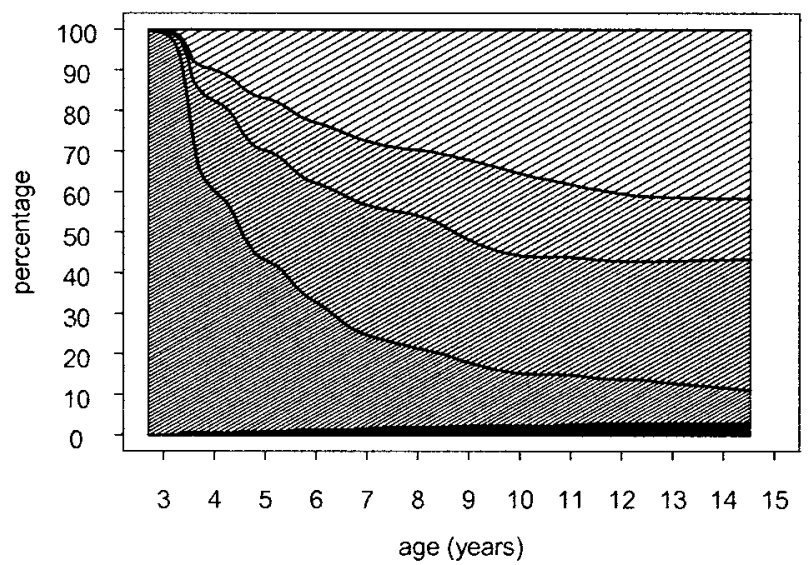

Walks well alone at least 20 feet Walks unsteadily alone

Walks with support or assistive devices

Does not walk

Died

Fig 3. Ambulation charts showing probabilities of various levels of ambulation with time for children who were initially nonambulatory at a mean age of 2.7 years, stratified according to early motor milestones at age 2 . Rolling refers to the ability to roll over from front to back or from back to front. Sitting refers to the ability to maintain a sitting position without support or the ability to achieve a sitting position on one's own.

vious studies found that 98 to $100 \%$ of children who could sit by age 2 eventually walked with or without support. ${ }^{3,7}$ Those studies were smaller, however, and others found that $>60 \%$ of children with cerebral palsy who eventually walked did not sit until after age $2 .{ }^{4}$ Although most previous studies defined sitting as the ability to maintain a seated position independently after being placed 
in this position by others, 3,7 not all studies provided a clear definition of sitting. ${ }^{4}$

In our study, the ability to maintain a sitting position independently at age 2 was a good prognostic sign for future ambulation. However, if a child was not also pulling to a stand at that age, then we found only a $50 \%$ chance of walking with or without support by age 6 . Among children who were both sitting and pulling to a stand at age $2,76 \%$ could walk with or without support by age 6 .

Our study is subject to a number of important limitations. First, children with milder motor dysfunction might have been preferentially lost to follow-up monitoring. This would result in a study population with a greater proportion of severely affected children, and the chance of walking would be higher than that depicted in our results. Second, compared with the ethnic composition of California described in the 2000 census $(60 \%$ white and $7 \%$ black), our cohort included a smaller proportion of whites $(35 \%)$ and an overrepresentation of blacks $(10 \%)$. Some of this discrepancy might be explained by the different coding systems used to record ethnicity and race, as well as by the increased prevalence of cerebral palsy noted among blacks. ${ }^{23,24}$ However, the ethnic disparity may also reflect the tendency of individuals of higher socioeconomic status to forego state-sponsored services in favor of other benefits that are available to them through private insurance or other means.

Other limitations include the fact that the interrater reliabilities of terms such as spastic quadriplegia and dystonic have not been adequately studied and the fact that specific details regarding the type of sitting (eg, "W-sitting") and the quality of ambulation were not available to us. In addition, our data did not include neuroimaging findings or the types of physical therapy and spasticity treatments received. Finally, our measure of ambulation ability did not provide information regarding the actual amount of time that the child walked in various conditions and environments. These limitations are offset by several strengths of the study, including the large numbers, the ability to provide prognostic information regarding several different levels of ambulation with time, and the analysis of several different types of clinical factors together in a multivariate model, to determine the most useful independent predictors of future ambulation.

In a comprehensive prospective study of gross motor function among 657 children with cerebral palsy, ${ }^{10}$ it was found that classification into 1 of 5 GMFCS strata was useful for predicting the ability to walk 10 steps unsupported. Specifically, children who functioned at the higher GMFCS levels (I and II) had an excellent chance of achieving this motor milestone, with the assumption that they stayed within their GMFCS levels with time, ${ }^{12}$ whereas less than one-half of children at GMFCS level III achieved this goal. Our results are consistent with those previous findings. Although we did not include children at GMFCS level I, because by definition those who could already walk at age 2 were excluded, our children who could sit independently and pull to a stand (GMFCS level II) had an $\sim 40 \%$ chance of achieving full ambulation by age 14, whereas very few of those who could roll but not sit independently (GMFCS level IV) eventually reached this goal.

Previous work suggested that, on average, children with cerebral palsy reach $90 \%$ of their motor potential (as measured with the GMFM-66) by age 5 and those with a greater degree of motor disability have gross motor function curves that plateau even earlier. ${ }^{10}$ Similarly, we found that, among those who achieved full ambulation by age 10, the majority had already done so by age 6 and almost all (96\%) were at least walking with support by age 6 .

For families and practitioners caring for children with cerebral palsy, the ambulation charts can provide useful information in a simple straightforward way. On the basis of a child's motor ability at age 2, the probability that a nonambulatory child will walk with or without support at any subsequent age through age 14 can be determined. Although it is impossible to say where any individual child will be in the range of ambulation potential with time, these probabilities derived from a large population of similarly affected children may help guide interventions such as physical therapy.

How ambulation potential changes as a child with cerebral palsy enters adolescence deserves additional study. Adults with cerebral palsy often experience a decline in walking ability, attributed to increasing fatigue, inefficiency of ambulation, or increased joint pains. ${ }^{25-27}$ However, this loss of ambulation is documented primarily among adults $>20$ years of age, and studies of ambulation among children rarely include adolescents. Our data suggest that, on average, children continue to gain ambulation potential into their early teens. This is consistent with the finding that some adults with cerebral palsy can improve in walking ability even into their early twenties. ${ }^{26}$ However, our study spanned a period of only 12 years, and a child who was 2 years of age at the beginning of the study could be monitored at most until 14 years of age. Additional work is needed to determine the prognosis for ambulation among children with cerebral palsy as they enter their teenage years.

\section{ACKNOWLEDGMENTS}

Y.W.W. was supported in part by Neurological Sciences Academic Development Award K12 NSO1692.

We thank the California DDS for its cooperation and Drs. Peter Rosenbaum, Donna Ferriero, and Tom Newman for their careful review of the manuscript.

\section{REFERENCES}

1. Badell-Ribera A. Cerebral palsy: postural-locomotor prognosis in spastic diplegia. Arch Phys Med Rehabil. 1985;66:614-619

2. Beals RK. Spastic paraplegia and diplegia: an evaluation of non-surgical and surgical factors influencing the prognosis for ambulation. $J$ Bone Joint Surg Am. 1966;48:827-846

3. da Paz AC Jr, Burnett SM, Braga LW. Walking prognosis in cerebral palsy: a 22-year retrospective analysis. Dev Med Child Neurol. 1994;36: 130-134

4. Molnar GE, Gordon SU. Cerebral palsy: predictive value of selected clinical signs for early prognostication of motor function. Arch Phys Med Rehabil. 1976;57:153-158 
5. Trahan J, Marcoux S. Factors associated with the inability of children with cerebral palsy to walk at six years: a retrospective study. Dev Med Child Neurol. 1994;36:787-795

6. Bleck EE. Locomotor prognosis in cerebral palsy. Dev Med Child Neurol. $1975 ; 17: 18-25$

7. Watt JM, Robertson CM, Grace MG. Early prognosis for ambulation of neonatal intensive care survivors with cerebral palsy. Dev Med Child Neurol. 1989;31:766-773

8. Palisano R, Rosenbaum P, Walter S, Russell D, Wood E, Galuppi B. Development and reliability of a system to classify gross motor function in children with cerebral palsy. Dev Med Child Neurol. 1997;39:214-223

9. Russell DJ, Rosenbaum PL, Cadman DT, Gowland C, Hardy S, Jarvis S. The Gross Motor Function Measure: a means to evaluate the effects of physical therapy. Dev Med Child Neurol. 1989;31:341-352

10. Rosenbaum PL, Walter SD, Hanna SE, et al. Prognosis for gross motor function in cerebral palsy: creation of motor development curves. JAMA. 2002;288:1357-1363

11. Russell D, Rosenbaum PL, Avery L, Lane M. The Gross Motor Function Measure: GMFM-66 and GMFM-88 (Users' Manual). London, United Kingdom: Mac Keith Press; 2002:159

12. Wood E, Rosenbaum P. The Gross Motor Function Classification System for cerebral palsy: a study of reliability and stability over time. Dev Med Child Neurol. 2000;42:292-296

13. Sala DA, Grant AD. Prognosis for ambulation in cerebral palsy. Dev Med Child Neurol. 1995;37:1020-1026

14. California Department of Developmental Services. Information about developmental disabilities. Available at: www.dds.ca.gov/general/ info_about_dd.cfm

15. California Department of Developmental Services. CDER Manual. Sacramento: California Department of Developmental Services; 1986
16. Harris CW, Eyman RK, Mayeda T. An Interrater Reliability Study of the Client Development Evaluation Report. Pomona, CA: California Department of Developmental Disabilities; 1983

17. Hosmer D, Lemeshow S. Applied Logistic Regression. New York, NY: Wiley; 1989

18. Aalen OO, Johansen S. An empirical transition matrix for nonhomogeneous Markov chains based on censored observations. Scand J Stat. 1978;5:141-150

19. Anderson PK, Borgan O, Gill RD, Keiding N. Statistical Models Based on Counting Processes. New York, NY: Springer-Verlag; 1993

20. Strauss D, Ashwal S, Shavelle R, Eyman RK. Prognosis for survival and improvement in function in children with severe developmental disabilities. J Pediatr. 1997;131:712-717

21. Strauss D, Shavelle R. An extended Kaplan-Meier estimator and its applications. Stat Med. 1998;17:971-982

22. Strauss DJ, Shavelle RM, Anderson TW. Life expectancy of children with cerebral palsy. Pediatr Neurol. 1998;18:143-149

23. Wu YW, Escobar GJ, Grether JK, Croen LA, Greene JD, Newman TB. Chorioamnionitis and cerebral palsy in term and near-term infants. JAMA. 2003;290:2677-2684

24. Murphy CC, Yeargin-Allsopp M, Decoufle P, Drews CD. Prevalence of cerebral palsy among ten-year-old children in metropolitan Atlanta, 1985 through 1987. J Pediatr. 1993;123:S13-S20

25. Bottos M, Feliciangeli A, Sciuto L, Gericke C, Vianello A. Functional status of adults with cerebral palsy and implications for treatment of children. Dev Med Child Neurol. 2001;43:516-528

26. Strauss D, Ojdana K, Shavelle R, Rosenbloom L. Decline in function and life expectancy of older persons with cerebral palsy. NeuroRehabilitation. 2004;19:69-78

27. Murphy KP, Molnar GE, Lankasky K. Medical and functional status of adults with cerebral palsy. Dev Med Child Neurol. 1995;37:1075-1084

\section{THE POLITICS OF CONSUMPTION}

"American output per worker hour increased by $60 \%$ from the 1870 s to 1900 . It rose again another $69 \%$ in the next 20 years. That productivity, more than legal reforms, became the base for the consumers' democracy. The decline of a political vision of social equality made a culture of mass consumption seem a natural and inevitable alternative. Increasingly more fragmented, mobile, and unorganized, Americans joined 'consumption communities' that did not require an active citizenry but were comprised, according to historian Daniel Boorstin, of 'people who have a feeling of shared well-being, shared risks, common interests, and common concerns that come from consuming the same kinds of objects.' Americans defined their status and dismissed boredom and anxiety by joining the crowd who bought Life Savers . . . or Lincolns."

Cross G. An All-Consuming Century. New York, NY: Columbia University Press; 2000

Submitted by Student 